\title{
SABERO: PARADIGMA DE LA CRISIS MINERA
}

\author{
Jesús SÁNCHEZ MELADO \\ Escuela Universitaria de Relaciones Laborales -Universidad de Valladolid
}

\begin{abstract}
RESUMEN: El objetivo de este trabajo es analizar los problemas que plantea el desarrollo alternativo de los territorios afectados por la crisis de la minería del carbón, tomando como referencia el caso de la cuenca leonesa de Sabero. Sin perder de vista la capacidad de la industria extractiva para configurar el espacio, se examinan las políticas diseñadas para afrontar el declive, haciendo especial hincapié en aquellos factores que permiten explicar su escaso éxito en el intento de detener la desarticulación económica, social y demográfica de la cuenca minera.
\end{abstract}

$\boldsymbol{P A L A B R A S C L A V E}$ : Minería, declive, desarrollo territorial, reestructuración, reindustrialización..

ABSTRACT: The aim of this work is to analyse the problems raised by the alternative development of the territories affected by the coal mining crisis, taking as reference the case of the Sabero coalfield in Leon. Keeping in mind the capacity of the extraction industry to configure space, the politics designed to deal with the decline are examined, emphasizing those factors that allow us to explain their limited success in trying to stop the economic, social and demographic disassembling of the coalfield

KEY WORDS: Mining, decline, territorial development, reorganization, reindustrialization..

$\boldsymbol{R} \boldsymbol{E} \boldsymbol{S} \boldsymbol{U} \boldsymbol{M} \boldsymbol{E}:$ : L'objectif de ce travail est d'analyser les problèmes que pose le développement alternatif des territoires touchés par la crise de l'industrie minière du charbon, en prenant comme référence le cas de Sabero (León). Sans perdre de vue la capacité de l'industrie extractive pour former l'espace, on examine les politiques conçues pour affronter la crise, en soulignant surtout les facteurs qui permettent d'expliquer leur faible succès dans la tentative d'arrêter la désarticulation économique, sociale et démographique du territoire minier.

MOTS-CLÉS: Industrie minière, crise, développement territorial, restructuration, réindustrialisation.

RESUMO: O presente trabalho tem como finalidade analisar os problemas apresentados pelo desenvolvimento alternativo dos territórios atingidos pela crise mineira do carvão, principalmente referidos ao vale mineiro leonês de Sabero. Considerando a capacidade da indústria extractiva para configurar o espaço, examinamos as políticas delineadas para solucionar o declive, mostrando o máximo interesse naqueles factores que permitem explicar o pouco êxito das tentativas de travar a desarticulação económica, social e demográfica das zonas mineiras.

PALAVRAS CHAVE: Minaria, declive, desenvolvimento territorial, reestruturação, reindustrialização.

\section{INTRODUCCIÓN.}

El presente artículo es fruto de una investigación más amplia realizada con el objetivo de analizar la crisis de la minería del carbón y sus efectos sobre el desarrollo de las cuencas mineras más orientales de la provincia de León: Valderrueda, Sabero y Ciñera-Matallana. 
Ante la realidad de unas comarcas desestructuradas y deprimidas en su dimensión social y económica, y con un medio ambiente muy deteriorado precisamente por la actividad en la que se había basado su desarrollo, las líneas básicas de la investigación se centraron en comprender el papel desempeñado por la industria del carbón en la configuración del espacio, desentrañar las claves de la reconversión minera y sus implicaciones territoriales, examinar las políticas de inversión del declive y calibrar la capacidad de adaptación de los territorios marginales a las nuevas circunstancias surgidas como consecuencia de la quiebra de su sustrato económico tradicional.

El estudio de las cuencas orientales leonesas ratificó la idea, por lo demás muy extendida, de que la industria nacional del carbón - ligada desde un principio a poderosos intereses económicos como el capital siderúrgico vasco, que impulsó el desarrollo de la minería leonesa a finales del siglo XIX - ha subsistido al socaire de un complicado entramado protector que le ha permitido transmitir su ineficiencia, en la forma de mayores costes energéticos, al resto de la industria y de la economía española.

En los años ochenta del siglo pasado, sin embargo, una serie de acontecimientos - el fin de la crisis energética, el cambio tecnológico, las normas de protección ambiental y la necesidad de adaptar los precios y las ayudas públicas a la normativa comunitaria - marcó el comienzo de un titubeante proceso de reestructuración, aún en marcha y de incierto resultado final.

En el escenario resultante, dominado por las pérdidas de las empresas y las ayudas públicas, encontrar algún argumento que justifique el mantenimiento de la minería nacional es desde luego complicado. El único que exhibe cierta coherencia es el que apela a los efectos regionales de su desmantelamiento. $\mathrm{Y}$ es que, efectivamente, la reconversión de los territorios mineros choca con el importante obstáculo de una realidad socioeconómica, fraguada por la propia actividad extractiva, que hace que sea muy problemática la diversificación económica de estas comarcas.

El ejemplo paradigmático del proceso de cambio territorial impulsado por la crisis carbonera lo tenemos en la cuenca de Sabero (integrada por los municipios de Sabero, Cistierna y La Ercina). Aquí, las nefastas consecuencias de la reestructuración obligaron a formalizar y definir los mecanismos de la reactivación antes que en el resto de las comarcas mineras leonesas, donde será preciso esperar hasta la segunda mitad de los años noventa para observar los primeros tímidos atisbos de desarrollo alternativo. De esta forma, la pequeña cuenca minera situada a orillas del Esla se convirtió en el escenario perfecto para analizar el papel que desempeñan, en la recomposición social y económica del espacio, 
tanto las políticas encaminadas a revertir el declive como las propias características del territorio.

\section{LA IMPRONTA DE LA MINERÍA EN EL TERRITORIO}

La historia de la minería en la cuenca hullera saberense es un excelente ejemplo de crecimiento económico insostenible y de los efectos sobre el territorio de una actividad que, durante más de 150 años, jugó un papel decisivo en su modelado, transformando sus características físicas, sociales, económicas y demográficas. Presente en la cuenca de Sabero desde el primer tercio del siglo XIX, la consolidación de la actividad extractiva provocó la marginación, en los municipios más directamente relacionados con ella, de los usos tradicionales del espacio, como la agricultura y la ganadería. Posteriormente, al compás de su evolución cíclica, el flujo y reflujo de los movimientos migratorios transfiguró la realidad social de la comarca y condicionó el desarrollo de su patrimonio inmobiliario y de la red de servicios. Especialmente desde 1892, cuando, con la creación de Hulleras de Sabero y Anexas, S. A., fue generándose progresivamente una clara supeditación del territorio a los intereses de la compañía que marcaría su devenir durante un siglo.

Aunque en ocasiones otras empresas mineras de cierta importancia a nivel local operaron también en la cuenca, ninguna llegaría a influir tanto en la conformación del territorio como Hulleras de Sabero. La mayoría, además, cerró sus puertas a lo largo de la década de los sesenta, cuando, tras el abandono de la autarquía, se encontraron sin capacidad de reacción ante la realidad de un petróleo barato y cada vez más demandado a causa del cambio tecnológico. Son los casos de Esteban Corral Sánchez, Malaquías Revuelta o Domingo López Alonso. Sólo Hulleras Oeste de Sabero logró superar esa época tan aciaga para la minería del carbón, y se mantuvo, hasta que cesó en la actividad en 1982, como acompañante único de Hulleras de Sabero. Pero el dominio de esta compañía en la cuenca fue siempre abrumador y, además, creciente. Si en 1940 aportaba el 68 por 100 de la producción y el 61 por 100 del empleo de la cuenca, cuarenta años más tarde esos porcentajes se elevaron hasta el 96 y el 97 por 100, respectivamente ${ }^{1}$.

Desde un principio, el gran problema de Hulleras de Sabero no fue otro que la extraordinaria complicación que presentaba la explotación de las capas de carbón de sus yacimientos. Unas dificultades que crecían sin cesar al agotarse las reservas más accesibles. De este modo, las condiciones geológicas llegaron

\footnotetext{
${ }^{1}$ Estadística General de Producción, Importación y Distribución Directa de Carbones Minerales.
} 
a ser tan desfavorables que se puede afirmar, sin ambages, que, a finales de los ochenta, el carbón se había agotado económicamente en la cuenca de Sabero. El mineral seguía existiendo en el subsuelo, pero los costes de extracción eran tan elevados que ni con las generosas ayudas públicas ni con la contribución de las explotaciones a cielo abierto -que habían sido iniciadas en 1979 y cuyo impacto ambiental aún permanece- era posible cubrirlos.

El cierre de las explotaciones subterráneas de Hulleras de Sabero resultaba, pues, inevitable. Fue, además, un acontecimiento que, pasados los primeros momentos de oposición, contó con el inusual beneplácito de todos los colectivos afectados, incluidos los 638 trabajadores de una plantilla que, en 1955, había llegado a los 2.000 efectivos, y que en 1987 aún rondaba los 1.000. Así, con el argumento de evitar más pérdidas, el cierre del pozo Herrera II, previsto en principio para finales de 1993, se adelantó dos años y se hizo realidad el 31 de diciembre de 1991.

A partir de ese día, la cuenca minera de Sabero se enfrentaría a un futuro plagado de problemas económicos, sociales y demográficos. El intento de solucionarlos daría lugar a uno de los procesos de reactivación más interesantes de cuantos han tenido lugar en las comarcas carboneras leonesas. No por sus frutos, sino por lo que tiene de paradigmático. Seguir su hilo conductor permite sacar a la luz los muchos obstáculos con los que se topa la reversión del declive minero.

Uno de ellos hunde sus raíces en la propia herencia de la minería, en las secuelas institucionales y psicológicas de un siglo de "monocultivo minero", que había conformado un territorio nada propicio para el asentamiento de nuevas actividades, un territorio que, a finales de los ochenta, era un claro ejemplo de "la desvitalización y la atonía del potencial empresarial propias de las economías regionales que gravitan sobre la gran empresa" (PASCUAL, 1993).

Si en la mayoría de las regiones articuladas alrededor de una empresa industrial de gran tamaño se observa el mencionado efecto depresor sobre la creación de nuevas actividades, este hecho es aun más evidente en el caso de los espacios vertebrados por la minería del carbón. En primer lugar, por los débiles efectos de eslabonamiento de la minería, y, en segundo, por la política seguida por las grandes compañías carboneras y, especialmente, por la impronta que deja su actividad en el territorio.

Las empresas carboneras se han enfrentado a menudo a problemas de escasez de mano de obra. La inmigración extranjera de los años setenta hacia los núcleos mineros, y el notable porcentaje que representan en la población de las cuencas mineras las personas no nacidas en ellas, son dos de los efectos más visibles 
de esa realidad. De hecho, según el Censo de Población y Viviendas de 1991, los habitantes de Sabero no nacidos en el municipio suponían el 62 por 100 de su población. La razón explicativa de las dificultades para cubrir los puestos de trabajo en la mina no es otra que su carácter en extremo penoso y peligroso, lo cual hace que, en no pocas ocasiones, su desempeño se considere un mal menor que se asume porque no existe otra alternativa. Muchas personas optarían por otra ocupación si esto fuera posible. Esta posibilidad es percibida como una seria amenaza por la compañía minera, que tratará de evitar el establecimiento de otras empresas que compitan con ella en la obtención de uno de los factores más vitales: la fuerza de trabajo.

No es de extrañar que, en estas circunstancias, la empresa fordista intente acaparar el mayor número posible de fases de la cadena de valor y rehuya exteriorizar servicios, lo cual limita las posibilidades de expansión de un sector terciario independiente. Hulleras de Sabero es un buen ejemplo de esta forma de actuar, puesto que, en 1989, era titular de 13 licencias fiscales, además de la relativa a la explotación de minas: cuatro de reparación, una de transporte de viajeros en autobús, una de transporte de viajeros en vehículos de turismo y siete de transporte de mercancías por carretera ${ }^{2}$.

En 1991, la actividad extractiva acaparaba en el municipio de Sabero el 54 por 100 del empleo. Ciertamente, este porcentaje, como consecuencia de la crisis del sector, había experimentado un importante descenso en los últimos años; en concreto había perdido casi 20 puntos porcentuales desde 1981. Pero aun así, en 1991, el peso del resto de los sectores, incluida la agricultura, no podía ser más que marginal. Sólo el terciario (fundamentalmente el comercio y los servicios públicos) alcanzaba cierta significación, si bien muy alejada de los niveles propios de una sociedad desarrollada.

La concentración del empleo en la minería acabó por configurar una mano de obra a la medida de la empresa carbonera: totalmente especializada y sin más conocimientos que los justos para desempeñar su función. Sin la flexibilidad necesaria, con una imagen de conflictividad y absentismo, y carente de iniciativa, la mano de obra se convirtió también en un factor depresor de la localización de nuevas actividades.

Esta situación se torna especialmente preocupante cuando, como suele suceder, la mentalidad reacia a las iniciativas empresariales se extiende y acaba impregnando al conjunto de la población. Esto es así porque la ausencia de una

\footnotetext{
${ }^{2}$ Cámara Oficial de Comercio e Industria de León: Censo de contribuyentes por licencia fiscal al 31 de diciembre de 1989.
} 
"atmósfera industrial" adecuada es algo más que un simple obstáculo, es un obstáculo que crece con el tiempo. Cuanto más tardíamente comience un territorio a desarrollar un clima favorable para el asentamiento empresarial, más probabilidades habrá de que otros espacios lo hayan generado o fortalecido. El progresivo establecimiento de unidades productivas en estos lugares potenciará sus economías externas y los convertirá, en detrimento del resto, en muy atractivos para las compañías que estén decidiendo su localización.

Pero, con ser fundamentales, las características negativas de la cuenca de Sabero de cara a su desarrollo alternativo no se limitaban a la ausencia de diversificación económica, a la presencia de una mano de obra especializada en la actividad en crisis, conflictiva y carente de iniciativa, o a la existencia de un marco institucional muy poco apropiado. El atractivo de un territorio para el asentamiento empresarial depende también de la calidad de sus infraestructuras, y en este aspecto encontramos factores adicionales que iban a entorpecer el proceso de reindustrialización en la cuenca de Sabero. En el territorio no existía suelo industrial convenientemente acondicionado, y la ubicación de la cuenca minera, lejos de los grandes ejes de comunicación, representaba un escollo añadido para la localización empresarial. Es cierto que una carretera nacional, la que enlaza León con Santander, cruza el municipio de Cistierna, pero las carencias de esta vía no permitían considerarla como un factor favorecedor del desarrollo. Por supuesto, las complicaciones de la carretera eran mucho mayores al norte de Cistierna, al discurrir por la abrupta orografía de la Zona Cantábrica; pero los 43 kilómetros que separan esta localidad de Mansilla de las Mulas, punto de engarce con la carretera nacional 630 León-Valladolid, eran también un elemento disuasorio para muchos empresarios.

En resumen, las características de la cuenca minera de Sabero definían un escenario muy complicado y reducían las posibilidades de éxito de cualquier intento revitalizador. Era necesario, en consecuencia, que éste se desplegara con la suficiente anticipación e intensidad para que se pudiera albergar alguna esperanza de salvar los importantes obstáculos que bloqueaban las escasas posibilidades de desarrollo. En lugar de eso, las medidas encaminadas a contrarrestar la crisis se pusieron en marcha tarde y fueron, casi exclusivamente, las que estaban disponibles con carácter general. Sin medidas adaptadas a la grave situación de la comarca la dinámica del cambio social siguió su curso, arrastrando tras de sí a la propia dirección del proceso, más inoperante cuanto más evidente era el fracaso de sus actuaciones.

No obstante, es posible distinguir tres fases en el proceso de reindustrialización de la cuenca de Sabero. La primera de dichas etapas, marcada por las actuaciones de la Mesa para la Reindustrialización del Área de Sabero, se prolongó hasta finales de 1995, y se caracterizó, además de por sus nulos resulta- 
dos, por lo inadecuado de los instrumentos empleados para revertir el declive. Durante la segunda, que abarcó los años 1996 y 1997, al amparo de las ayudas MINER llegaron a la cuenca buena parte de los escasos proyectos que hoy conforman la base de su estructura productiva. La tercera etapa, determinada por la aplicación del Plan de la Minería del Carbón y Desarrollo Alternativo de las Comarcas Mineras (1998-2005), se concretó, fundamentalmente, en una mejora de las infraestructuras del territorio.

\section{EL FRACASO DE LA MESA DE SABERO}

Con el objetivo de conseguir la recolocación de los 430 ex mineros de Hulleras de Sabero que, tras el cierre de las explotaciones subterráneas, iban a quedar a la espera de un puesto de trabajo, el 13 de noviembre de 1991 se constituyó la Mesa para la Reindustrialización del Área de Sabero ${ }^{3}$. La idea principal consistía en tratar de atraer inversiones productivas ofreciendo a sus promotores diversos incentivos (CUADRO 1). De ellos, los tres primeros tenían carácter general, de modo que, por ser las únicas vinculadas exclusivamente al proceso de reindustrialización de la cuenca de Sabero, sólo las subvenciones procedentes de la Diputación y de Hulleras de Sabero se pueden considerar verdaderas ayudas de la Mesa.

La Diputación Provincial de León se comprometió a destinar, al menos, 400 millones de pesetas para conceder una ayuda de un millón de pesetas por trabajador recolocado (independientemente de que fuera ex minero o no tuviera tal consideración), dotar de infraestructuras a los terrenos sobre los que se asentaran las industrias y, si existiera sobrante, subvencionar intereses.

El Fondo Minero, aportado por la compañía carbonera, ascendía a 775 millones y era una parte de la ayuda percibida por Hulleras de Sabero como compensación al abandono de la actividad carbonera. La aplicación de este incentivo era muy simple: Hulleras de Sabero concedería ayudas por la recolocación de los mineros que hubieran perdido su empleo como consecuencia del cierre del pozo Herrera II, con un límite de 2,5 millones de pesetas por trabajador.

La contribución de la compañía minera a la reindustrialización se completaba con los demás compromisos asumidos en los acuerdos con sus trabajadores,

\footnotetext{
${ }^{3}$ La plataforma encargada de dirigir la recomposición económica de la cuenca minera estaba integrada por representantes de la Junta de Castilla y León, la Diputación Provincial de León, los Ayuntamientos de Sabero, Cistierna y La Ercina, la Empresa Nacional de Innovación (ENISA), Hulleras de Sabero, y el comité de empresa de esta compañía, que se convertiría en el comité de seguimiento del proceso. El 18 de febrero de 1992, la Dirección General de Minas entró a formar parte también de la Mesa y quedó excluida de la misma ENISA.
} 
consistentes en la cesión gratuita de antiguas infraestructuras mineras. Entre ellas estaban los terrenos y las instalaciones del pozo Herrera I, que fueron los elegidos, en un principio, para el asentamiento de las empresas.

El hecho de que la cuantía de las subvenciones estuviera en función del número de puestos de trabajo creados, las hacía especialmente interesantes para pequeños proyectos empresariales intensivos en mano de obra. Sin embargo, su relevancia era menor cuando se trataba de proyectos de mayor magnitud y de elevada relación entre inversión y empleo. En cualquier caso, si enmarcamos el proceso de reindustrialización de Sabero en el contexto de una abierta competencia de distintos territorios por atraer actividades productivas, las ayudas específicas de la Mesa resultaban totalmente insuficientes para que la comarca fuera percibida por los emprendedores como un buen lugar para crear y mantener a largo plazo una ventaja competitiva. Esta percepción depende básicamente de las características y activos del territorio (cultura empresarial, mano de obra y otros factores productivos, infraestructuras para producir y vivir, etc.) un aspecto en el que la posición de partida de la cuenca minera era muy desfavorable. Ante esta realidad, las ayudas de la Diputación y de Hulleras de Sabero no lograrían evitar que los empresarios con vocación de futuro optaran por emplazamientos más adecuados para sus proyectos.

Cuadro 1. Ayudas a las que podian optar las empresas que se ubicaran en la cuenca de Sabero

\begin{tabular}{lllll}
\hline \multicolumn{1}{c}{ Ayuda } & (1) & \multicolumn{1}{c}{ Importe } & $\begin{array}{c}\text { Limites sobre } \\
\text { la inversión }\end{array}$ \\
\hline Incentivos Regionales & (a) & 22,5\% de la inversión (estimación) & $70 \%$ & $50 \%$ \\
Incentivos Territoriales & (b) & 25\% de la inversión & $70 \%$ & $50 \%$ \\
Incentivos Agrarios & (b) & Hasta el 20\% de la inversión & $70 \%$ & $50 \%$ \\
Diputación Provincial & (c) & Un millón por puesto de trabajo & $70 \%$ & $50 \%$ \\
Fondo Minero & (d) & Hasta 2,5 millones por ex minero recolocado & $70 \%$ & \\
Casión de terrenos y naves & (d) & & & \\
\hline
\end{tabular}

(1), Procedencia: (a) Administración Central; (b), Junta de Castilla y León; (c), Diputación Provincial; (d), Hulleras de Sabero

FUENTE: Actas de la Mesa para la Reindustrialización del Área de Sabero

El sistema de incentivos no sólo era insuficiente, sino que, además, no podía ser más rudimentario. En ningún momento se planteó la cuestión de cuáles eran las inversiones que, por sus efectos de arrastre, debían considerarse prioritarias. Es evidente que cualquier proyecto capaz de generar puestos de trabajo es bienvenido a una zona con problemas de desarrollo; pero hay otros factores que también resultan fundamentales, como que la empresa demande productos locales, subcontrate fases de su proceso productivo con compañías de la zona o se preocupe por la formación profesional de sus trabajadores. Es posible que, dadas las características de la comarca, existiera el convencimiento de que su po- 
tencial de desarrollo endógeno era nulo, y que, por tanto, ante la improbabilidad de una respuesta desde el interior del territorio a las cuestiones citadas, éstas carecían de interés. Pero esta circunstancia no invalida la crítica al sistema de ayudas, puesto que, en primer lugar, no se intentó evaluar el potencial de desarrollo endógeno, y, en segundo, tampoco se optó por la línea de actuación más lógica cuando no existe ninguna posibilidad de desarrollo desde dentro: concentrar todos los esfuerzos en atraer un gran proyecto empresarial.

Se puede considerar que Sabero representa el reverso de las ideas HIRSCHMAN (1958). Si, según este autor, la intervención pública encaminada a promover el desarrollo de las regiones más atrasadas debe analizar las alternativas de inversión para elegir la secuencia más eficaz de cara a promover el desarrollo, en el caso de la cuenca minera, la escasa determinación y la falta de criterio de las medidas encaminadas a revertir el declive del territorio no permitieron frenar su acelerado deterioro social y económico. En este sentido, la incapacidad de la Administración para poner en marcha una política de reactivación coherente, especialmente durante los cinco años que siguieron al cierre de las minas, se convertirá en una causa adicional del fracaso de la reindustrialización.

Las importantes cuestiones relativas a la definición y al ámbito territorial de las ayudas centraron prácticamente toda la atención de la Mesa de Sabero durante sus dos primeros meses de vida. Así, si exceptuamos a EXMIVOSA, la empresa catalana subcontratada por Hulleras de Sabero para explotar el cielo abierto de Sotillos, el año 1991 concluía sin que ni una sola nueva empresa se hubiera asentado en la comarca.

En consecuencia, se puede afirmar que el proceso careció de un horizonte temporal suficientemente amplio y de la necesaria coordinación entre el desmantelamiento de la minería y el esfuerzo reindustrializador. Se trata de una faceta de la política de inversión del declive que redujo las posibilidades de regeneración del tejido económico y social de la cuenca minera, y que incluso puede explicar la inconsistencia de la propia política. La gestión efectiva del declive de un territorio requiere un diagnóstico precoz de la crisis para, de esta forma, poder planificar intervenciones a largo plazo que permitan sincronizar la mengua del sector en dificultades y la actuación reindustrializadora, evitando entre ellas un desfase excesivo que reduzca las posibilidades de éxito o haga que la reversión del declive sea simplemente imposible. Sin embargo, en Sabero faltó la segunda etapa de las tres que, según DAYNAC (1996), cabe distinguir en cualquier proceso reconversor. De la fase "A", o de colapso, que comenzó con el anuncio del cierre de Hulleras de Sabero, se pasó directamente a la "C", o de reconstrucción, sin que mediara la fase "B", o de conflicto, caracterizada por el asentamiento de nuevas actividades mientras seguía en activo la empresa en crisis. 
Con estas premisas, casi al mismo tiempo que se celebraba la última reunión de la Mesa del año 1991, una orden ministerial de 27 de diciembre suspendió el servicio de viajeros por ferrocarril entre León y Bilbao. El mal estado del material, que no permitía realizar el viaje en las condiciones de seguridad exigidas, determinó el cierre de la histórica línea del ferrocarril de La Robla, la línea que, a finales del XIX, había impulsado el desarrollo de las cuencas mineras leonesas situadas al este del Bernesga. Para el tema que nos ocupa, este hecho es un buen ejemplo del desmantelamiento de los servicios generado por la crisis del carbón. Un desmantelamiento progresivo que iría intensificando las negativas peculiaridades de la cuenca de Sabero para la localización empresarial.

A lo largo de los cuatro años siguientes, la Mesa aprobó un total de 37 proyectos, que, en conjunto, preveían unas inversiones de más de 7.000 millones de pesetas y se comprometían a crear 534 puestos de trabajo, de los cuales 437 serían ocupados por ex-mineros de Hulleras de Sabero (CUADRO 2). La mayor parte recibió el visto bueno en 1992; sin embargo, al finalizar 1995 sólo estaban funcionando 16 iniciativas empresariales, con 56 empleos y unas inversiones de 552 millones de pesetas (CUADRO 3). En la enorme desproporción entre esta realidad y las expectativas, tuvieron mucho que ver las dificultades con que se encontraron los empresarios a la hora de presentar las garantías exigidas para poder disponer de las ayudas aprobadas.

En el caso de los incentivos regionales y territoriales, eran dos las dificultades: la exigencia de una autofinanciación mínima del 30 por 100 de la inversión aprobada y el hecho de que no fuera posible el pago anticipado de la subvención. Esto, en definitiva, suponía que los incentivos no servían realmente para financiar la realización del proyecto, sino para recuperar una parte de la inversión una vez que ésta había sido ejecutada y que la Administración comprobaba que se habían cumplido los requisitos, algo que normalmente podía demorarse varios meses desde la conclusión del proyecto. En consecuencia, el empresario debía disponer de recursos suficientes para financiar su iniciativa, incluyendo también la parte cubierta con los incentivos. La figura del crédito anticipo paliaba en parte este problema al abrirle al promotor la posibilidad de disponer anticipadamente del importe de la ayuda, pero para ello era preciso aportar avales que garantizaran la finalización de la inversión.

Para liberar los recursos del Fondo Minero se exigía también un aval que garantizara, durante tres años, el mantenimiento de los puestos de trabajo, y, de la misma forma la Diputación requería garantías para hacer efectiva su ayuda. Por lo general, en estos dos casos, pasaban varios meses desde la presentación del aval hasta la percepción de la subvención. 
Si bien es cierto que exigir avales que garanticen el cumplimiento de los compromisos adquiridos resulta necesario para evitar las maniobras de aquéllos que únicamente persiguen el cobro de la subvención, no lo es menos que, en casos excepcionales como el que nos ocupa, es conveniente arbitrar mecanismos más flexibles, aun corriendo riesgos de incumplimiento, pues de lo contrario una mayoría de proyectos se verá abortada ante la imposibilidad de sus promotores de aportar las garantías exigidas o de disponer de los recursos precisos para acometer la inversión. Las específicas características de la cuenca minera de Sabero -que la configuraban como un área marginal, no sólo en el contexto del tejido industrial español, sino incluso dentro de la débil estructura productiva leonesa- determinaban que no fueran precisamente los grandes y solventes empresarios los que decidieran asentar en ella sus proyectos. Con algunas excepciones, la característica más destacable de los empresarios dispuestos a ubicarse en la comarca era su debilidad financiera, de donde se infiere la improbabilidad de que sus proyectos pudieran salir adelante con el apoyo de los mecanismos de reactivación existentes.

Los primeros abandonos provocados por las dificultades económicas y financieras no tardaron en producirse: en enero de 1993 cerraron sus puertas New Battle y Construcciones Metálicas Sabero. A partir de ese momento, la lista de desistimientos no haría otra cosa que crecer: Embutidos Picos de Europa, Montajes Metálicos Ferrán, Premontex y Construcciones, Tarcosa, Riberesla, SegurEsla, Alejandro Díez, Herminio Cuesta, Jesús Triviño, etc. Incluso la explotación a cielo abierto cerraría sus puertas en 1993, dos años después de haberlo hecho la subterránea. Hulleras de Sabero no consiguió firmar con las compañías eléctricas un nuevo contrato para el suministro de carbón. De esta forma, el proceso de reindustrialización se vio privado de los posibles beneficios que durante 1994 pudiera haber generado esta actividad ${ }^{4}$.

En febrero de 1993, a la vista de que ninguno de los proyectos aprobados hasta entonces contaba con posibilidades de presentar los avales oportunos, la Mesa tomó el acuerdo de recurrir a las sociedades de garantía recíproca SOGACAL y SOTECA para que analizaran los aspectos financieros de los proyectos, emitieran los informes correspondientes y avalaran aquéllos que resultaran viables. En el primer informe presentado por estas sociedades, se analizaron cuatro proyectos y en todos la conclusión fue la misma: su difícil viabilidad. De esta forma, sin conseguir grandes avances, la complejidad burocrática del proceso aumentó. El propio representante de estas sociedades puso el dedo en la llaga al afirmar que "es una barbaridad que todas las ayudas tengan que venir

\footnotetext{
${ }^{4}$ Según los acuerdos entre Hulleras de Sabero y los trabajadores, la empresa se comprometía a ceder los beneficios obtenidos en la explotación a cielo abierto durante 1994 .
} 
avaladas, pues hace poco operativo dicho planteamiento ya que no creemos que haya nadie dispuesto a soportar todo el riesgo"5. Es cierto que la situación mejoró cuando en el mes de septiembre la Junta de Castilla y León constituyó con 300 millones de pesetas un fondo de garantía especial para respaldar los avales de las sociedades de garantía recíproca. A partir de entonces, algunos empresarios pudieron empezar a disponer anticipadamente de algunas subvenciones. Sin embargo, la dotación del fondo era claramente insuficiente, téngase en cuenta, por ejemplo, que una sola empresa, Conformados Metalgráficos, había solicitado avales por 266 millones de pesetas.

Cuadro 2. Proyectos aprobados por la Mesa para la Reindustrialización del Área de Sabero.

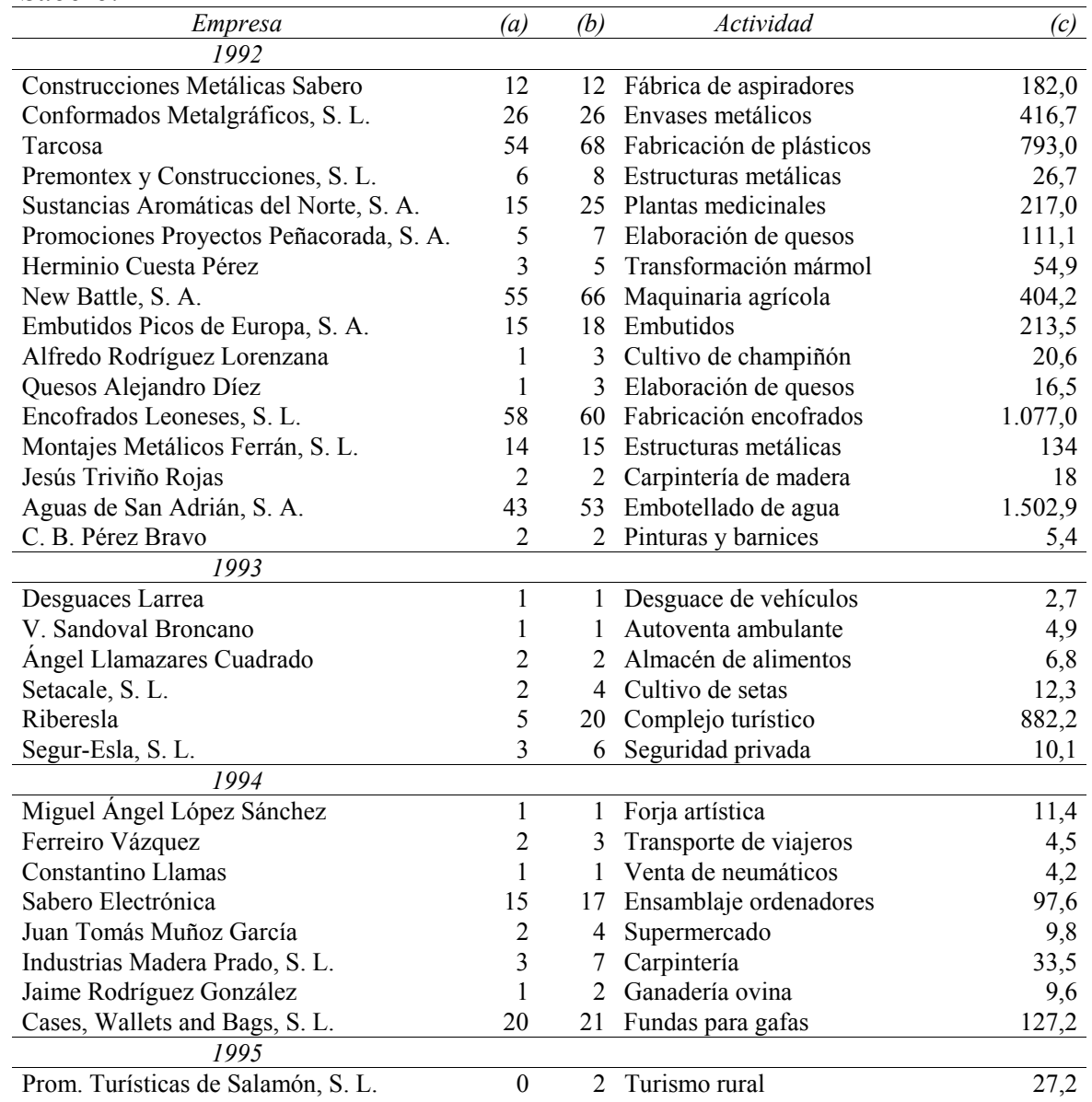

\footnotetext{
5 Acta de la reunión de la Mesa de fecha 16 de marzo de 1993.
} 


\begin{tabular}{lrrlr} 
Teodoro Prieto Pando & 1 & 1 & Carpintería & 6,9 \\
Eduardo Amblar López & 1 & 1 & Distribución de pan & 1,4 \\
Construcciones Electro. Sabero S. L. & 38 & 40 & Monitores ordenadores & 387,9 \\
Ferbis & 1 & 1 & Excavaciones \\
Miguel Blanco Fernández, C. B. & 1 & 1 & Fontanería & 6,7 \\
Aceros Especiales del Bidasoa, S. L. & 24 & 25 & Aceros y maquinaria & 3,9 \\
\hline \multicolumn{1}{c}{$\quad 1996$} & 1 & 1 & Transporte de viajeros & 322,8 \\
\hline Carlos García Tejerina & 1 & 2 & Bar \\
Juan Luis Niembro Prieto & 12 & 21 & Embalaje industrial \\
Envases Naturales, S. A. & 10 & 20 & Envasado de legumbres & 4,1 \\
SEPORLESA & 1 & 3 & Mesón & 5,1 \\
Hosteleros Leoneses, S. L. & 15 & 24 & Complejo cárnico & 541,1 \\
NEAL, S. A. & 1 & 2 & Elaboración de morcillas & 501,0 \\
Jesús Moreiras Fernández & 4 & 6 & Materiales construcción & 8,0 \\
Perfiles y Láminas de Cistierna, S. L. & \multicolumn{1}{c}{ 1997 } & 1 & 3 & Distribución de gasóleos \\
\hline \multicolumn{1}{c}{ TOTALES } & 483 & 616 & 12,2 \\
\hline Combustibles San Guillermo & & 110,3 \\
\hline
\end{tabular}

(a) Empleo ex mineros; (b), empleo total; (c), Inversión en millones de pesetas FuENTE: Actas de la Mesa para la Reindustrialización del Área de Sabero

Los graves problemas que atenazaban el proceso de reindustrialización condicionaron el funcionamiento de la Mesa, cuyas reuniones, ante la escasez de proyectos importantes sobre los que pronunciarse, se separaban cada vez más en el tiempo. De nada sirvió el acuerdo inicial de celebrar las reuniones cada mes, o, al menos, no fue suficiente para evitar que, por ejemplo, transcurriera casi un semestre desde la última de 1993 hasta la primera de 1994, o que, en 1995, la Mesa sólo se reuniera en dos ocasiones.

En este deficiente funcionamiento de la plataforma encargada de dirigir la reindustrialización, también desempeñaron un papel destacado el elevado número de sus miembros y la gran variedad de intereses, en ocasiones contrapuestos, que en ella se concitaban. Ya con anterioridad a la celebración de la reunión constituyente, se produjeron claras muestras de que éste iba a ser uno de los principales problemas. Así, los enfrentamientos entre la Diputación y la Junta de Castilla y León sobre una cuestión tan nimia como el lugar donde deberían celebrarse las reuniones ${ }^{6}$, fueron el primer síntoma evidente de las difíciles relaciones que iban a mantener, durante los primeros años, la Administración regional y la provincial. La inoperancia de la Mesa y su cada vez más acentuada inactividad no pueden entenderse sin tener en cuenta el clima de abierto conflicto entre sus integrantes. La eficiencia, por el contrario, reclamaba otro enfoque. Un enfoque que dejara las riendas de la reindustrialización en manos de un único responsable, dotado de la capacidad técnica y negociadora que tan complica-

\footnotetext{
${ }^{6}$ Diario de León, 7 de noviembre de 1991.
} 
do proceso precisaba. Son muchos los trabajos que enfatizan que la necesidad de un agente director es la nota común a las diversas fases de un proceso de reconversión (DAYNAC, 1996). La conveniencia de movilizar todos los recursos disponibles, que, en general, estarán en poder de una pluralidad de actores (Administración central, regional, provincial, local, empresa privada, sindicatos, partidos políticos, etc.), exige un coordinador eficiente que haga posible la cooperación y la actuación en la misma dirección de los diversos intereses -muchas veces contradictorios- implicados en el proceso. En cambio, la Mesa no tardaría en convertirse en un claro ejemplo de la ineficacia que, según HIRSCHMAN $(1958,208)$, se manifiesta "en la promulgación de planes de desarrollo que nadie toma en serio, en el establecimiento de reformas abortivas e instituciones muertas al nacer".

Ante un escenario tan poco propicio para hacer frente a la crisis, sólo es posible destacar, en esta primera fase de la reindustrialización, tres aspectos positivos, dos de los cuales desempeñarán un papel notable en el futuro desarrollo de la cuenca.

El primero fue la conclusión del polígono de Vidanes. Su inauguración oficial el 1 de diciembre de 1994 permitió que la comarca, tres años después del cierre de Hulleras de Sabero, dispusiera de una interesante oferta de suelo para el asentamiento de empresas: 142.321 metros cuadrados perfectamente urbanizados, situados junto a la carretera N-625 y divididos en 87 parcelas que se ofertaban a precios que oscilaban entre las 3.250 y las 3.750 pesetas el metro cuadrado $^{7}$.

El segundo se sitúa también en 1994, año en que empezó a tomar forma la idea de crear, en las instalaciones del complejo de San Blas ${ }^{8}$, un museo minero de ámbito regional que sirviera como revulsivo a la deprimida economía de la comarca. Unos años antes, en 1991, las gestiones realizadas por el Ayuntamiento de Sabero habían desembocado en la declaración de Bien de Interés Cultural, con la categoría de Monumento ${ }^{9}$, del conjunto formado por la Plaza Cerrada

\footnotetext{
${ }^{7}$ Diario de León, 1 de diciembre de 1994.

${ }^{8}$ Se trata de las instalaciones del primer horno alto de cok que existió en España, construidas en Sabero por la Sociedad Palentina Leonesa de Minas en 1847. Del complejo de San Blas aún se conservan la lonja de laminación, la casa de máquinas soplantes (transformada en vivienda), los restos de los hornos altos (llegó a haber dos), La Casona (chalet donde se ubicaron las oficinas y la dirección) y los cuarteles Viejos o del Rebedul. Elementos todos de un indudable valor histórico, pues constituyen el legado del único complejo siderúrgico de su género que se conserva en España (VIDAL Y ÁlVAREZ, 2002).

${ }^{9}$ Decreto 357/1991, de 26 de diciembre, de la Junta de Castilla y León (BOCyL 250 de 31 de diciembre).
} 
(nave de forja y laminación de la ferrería de San Blas) y los restos del alto horno, incluyendo La Casona y los cuarteles Viejos. Pero el proceso de creación del museo devendría largo y difícil.

Finalmente, ante la evidencia de que los problemas financieros seguían constituyendo un escollo insalvable para la localización empresarial en la comarca minera, y de que las empresas que pretendían instalarse en ella llevaban incorporado un riesgo excesivo para el volumen de recursos propios de las sociedades de garantía recíproca, la Junta de Castilla y León intentó limar estas dificultades articulando un sistema de "contragarantías" 10 . En su virtud, desde mayo de 1995, la Administración autonómica podría afianzar, en efectivo y de manera individualizada, las operaciones de riesgo que asumieran las sociedades de garantía recíproca con las pequeñas y medianas empresas que pretendieran instalarse en los términos municipales de Sabero, Cistierna y La Ercina. El importe máximo de la fianza se fijó en el 75 por 100 de la cuantía de la operación ${ }^{11}$.

\section{LA IMPORTANCIA DE LAS AYUDAS MINER (1996-1997)}

En 1996, el programa de reactivación económica de las cuencas mineras -contenido en el Plan de Modernización, Racionalización, Reestructuración, y de Reducción de Actividad de la Industria del Carbón-, con un fondo insuficiente (10.000 millones de pesetas anuales destinados a todas las comarcas mineras), pero claramente superior al disponible hasta entonces, supuso un impulso al desarrollo alternativo de los territorios afectados por la crisis carbonera.

Al amparo de esta normativa -que en el caso de los proyectos empresariales contemplaba la posibilidad del cobro anticipado de las ayudas y una notable agilidad en su tramitación- llegó a la cuenca de Sabero buena parte de los escasos proyectos que hoy forman la base de la estructura productiva del territorio. Se abrió, así, una nueva fase en el intento de reversión del declive. Una fase en la que se alcanzaron unos resultados más positivos, aunque insuficientes para detener el colapso de la comarca.

En el CUADRO 2 podemos observar cómo en 1996, aunque fueron pocos los proyectos aprobados por la Mesa, tanto el empleo como la inversión previstos en ellos fueron mayores que en 1994 ó 1995. Y lo que es más importante, de los

${ }^{10}$ Decreto 81/1995, de 4 de mayo, por el que se regula la prestación de fianzas individualizadas a cuenta de los socios partícipes de las sociedades de garantía recíproca, pequeñas y medianas empresas que pretendan instalarse en la cuenca minera de Sabero (BOE 88 de 10 de mayo).

${ }^{11}$ Este sistema específico para Sabero estuvo en vigor hasta que, en noviembre de 1997, fue derogado por el Decreto 232/1997 al quedar vacío de contenido ante las competencias conferidas a la Agencia de Desarrollo Regional. 
tres proyectos principales aprobados ese año, dos saldrían adelante, convirtiéndose en parte fundamental de la débil estructura económica del territorio.

Es muy posible que fuera la mayor efectividad del nuevo sistema estatal de ayudas el factor que terminó vaciando de contenido la actividad de la Mesa de Sabero. Después de más de cinco años de conflictivas reuniones y escasos resultados, la puesta en marcha de unas medidas de carácter general encaminadas a la reactivación de las comarcas mineras permitió poner punto y final a una plataforma que, a decir verdad, prácticamente había caído en el olvido después de que, durante sus primeros años de vida, hubiera despertado una gran expectación en toda la provincia.

Pero la Mesa no se disolvió formalmente: simplemente dejó de reunirse. Cuando se celebró la última reunión de la que tenemos noticia el 2 de abril de 1997, todavía quedaban más de 300 ex mineros sin recolocar. Ese día, la Junta de Castilla y León proporcionó a los asistentes información sobre una importante iniciativa que tenía muchas posibilidades de establecerse en la comarca: un complejo agroganadero de alta tecnología que supondría una inversión de 7.000 millones de pesetas y generaría cien puestos de trabajo. Su promotor, ENERVISA, había solicitado las ayudas MINER, una nueva prueba de la importancia de este mecanismo.

Cuadro 3. Proyectos en funcionamiento en la cuenca de Sabero a finales de cada año, 1992-1997

\begin{tabular}{lcrc}
\hline \hline & Proyectos & Empleo & Inversión $^{(I)}$ \\
\hline \hline 1992 & 1 & 2 & 182,0 \\
1993 & 5 & 11 & 45,9 \\
1994 & 11 & 29 & 116,1 \\
1995 & 16 & 56 & 551,9 \\
1996 & 20 & 65 & $1.118,9$ \\
1997 & 23 & 88 & $1.649,8$ \\
\hline \hline
\end{tabular}

(1) millones de ptas.

FUENTE: Actas de la Mesa para la Reindustrialización del Área de Sabero

Los resultados obtenidos por la Mesa de Sabero desde su constitución, a finales de 1991, hasta que dejó de reunirse en 1997, ponen de manifiesto su escasa eficacia en la reconstrucción económica de la comarca. En sus 22 reuniones (CUADRO 2), la Mesa aprobó un total de 46 proyectos empresariales, que con una inversión global de casi 9.000 millones de pesetas preveían generar 616 puestos de trabajo, 483 de los cuales serían ocupados por ex mineros de Hulleras de Sabero. Ahora bien, al concluir 1997 únicamente la mitad de esos proyectos había salido adelante, lo que supuso una inversión total de 1.650 millo- 
nes de pesetas, y la creación de 88 puestos de trabajo (65 ocupados por exmineros de Hulleras de Sabero). El 86 por 100 de los proyectos (19 de los 22) correspondían a empresarios autónomos o microempresas. Únicamente las iniciativas de Conformados Metalgráficos, SEPROLESA y NEAL (que no finalizará su inversión hasta 1998) representaban proyectos de mayor envergadura. La mayor parte de los proyectos se encuadraban dentro del sector servicios (60,87 por 100), aunque casi el 65 por 100 del empleo generado y más del 90 por 100 de la inversión correspondían a iniciativas industriales, dentro de las cuales predominaban las actividades agroalimentarias.

La proporción de fracasos más alta se dio entre los proyectos de mayor tamaño, como lo demuestra el hecho de que el empleo efectivamente creado hasta 1997 sólo representara el 14 por 100 del aprobado, o que la inversión realizada apenas alcanzara el 19 por 100 de la prevista en los proyectos que habían recibido el visto bueno de la Mesa. Por regla general, las causas del fracaso estaban relacionadas, como hemos tenido ocasión de comprobar, con la escasa capacidad financiera de los promotores y las dificultades para disponer anticipadamente de las ayudas concedidas. En 1997, por consiguiente, el fracaso del proceso de reversión del declive no admitía dudas.

Los parcos resultados del proceso de reindustrialización obligaban a buscar otras vías en las que basar el desarrollo de la cuenca minera. El legado patrimonial de la industria carbonera, con su indudable potencial de atracción, constituía una buena opción y las distintas instancias implicadas en el proceso de recomposición económica de la comarca retomaron el proyecto del museo minero. En noviembre de 1996, la Consejería de Educación y Cultura convocó un concurso para la redacción del proyecto de restauración de la ferrería de San Blas y su entorno ${ }^{12}$. El objetivo consistía en aprovechar el patrimonio arqueológico industrial de Sabero y ubicar en el municipio el Museo Regional de la Minería. A pesar del carácter deficitario de este tipo de proyectos ${ }^{13}$, la idea era atrayente porque entrañaba la recuperación del patrimonio y podía suponer, por sus potenciales efectos de arrastre, un impulso a la economía de la zona. El gran problema fue que aquel primer paso que se dio en 1996 careció de continuidad,

\footnotetext{
${ }^{12}$ Resolución de 4 de noviembre de 1996, de la Consejería de Educación y Cultura (BOCyL 222 de 15 de noviembre). La adjudicación recayó, un mes más tarde, en Alfonso Valmaseda González-Mata (Resolución de 13 de diciembre de 1996, de la Consejería de Educación y Cultura, BOCyL 8 de 14 de enero de 1997). El importe de la adjudicación fue de 27.862.968 pesetas.

${ }^{13}$ En uno de los informes sobre el Museo (CELIS ET AL, 1997) se estiman los gastos anuales de funcionamiento (con una plantilla de 25 personas) en 73 millones de pesetas, mientras que los ingresos previstos por los diversos conceptos (entradas, cafetería, librería, etc.) ascienden a 20 millones (con una previsión de 35.000 visitas y unos precios de la entrada entre 100 y 200 pesetas).
} 
y el proyecto se sumió en un marasmo del que no comenzaría a salir hasta ocho años más tarde.

\section{LA MEJORA DE LAS INFRAESTRUCTURAS AUSPICIADA POR EL PLAN DEL CARBÓN}

La desaparición de la Mesa para la Reindustrialización del Área de Sabero se produjo nueve meses antes de que entrara en vigor el Plan del Carbón. Para la cuenca minera, la nueva fase que se abre con este acuerdo supondrá la mejora de algunas infraestructuras y el relanzamiento del proyecto del museo minero; pero, paradójicamente - aunque las ayudas al desarrollo alternativo de los territorios carboneros experimentaron un fuerte impulso y su cuantía anual sextuplicó a la de los dos ejercicios precedentes-, el proceso de localización empresarial se limitará a la consolidación o la ampliación de las inversiones atraídas con las ayudas MINER, sin que, al concluir 2005, se hubieran asentado en la cuenca empresas significativas, distintas e independientes de las que ya habían manifestado su intención de hacerlo en 1997.

Cuadro 4. Actuaciones del Programa de Infraestructuras del Plan del Carbón en la cuenca de Sabero

\begin{tabular}{lrcc}
\hline \hline & Coste $(\epsilon)$ & Año de la firma & Sit. 31/12/2005 \\
\hline \hline Carreteras & & & \\
\hline \hline CL-626: Cistierna-Pte. Almuhey & 4.689 .231 & 1998 & Finalizado \\
CL-626: Boñar-Cistierna & 18.451 .072 & 1999 & Finalizado \\
CL-626: variante de Cistierna & 7.300 .000 & 2005 & No iniciado \\
Red provincial & 994.199 & $2001 / 2002 / 2005$ & En ejecución \\
\hline \hline Suelo industrial & & & \\
\hline \hline Ampliac. polígono en Cistierna & 555.555 & 2004 & No iniciado \\
Ampliación polígono en Sabero & 555.555 & 2004 & No iniciado \\
\hline \hline Infraestructuras turísticas & & & \\
\hline \hline Ag. bravas Crémenes-Cistierna & 600.000 & 2004 & No iniciado \\
Museo Regional de la Minería & 6.336 .757 & 2004 & En ejecución \\
C. Interpr. Valsemana & 500.000 & 2005 & No iniciado \\
\hline \hline Medio ambiente & & & \\
\hline \hline Cistierna & 768.841 & $2000 / 2004$ & Finalizado \\
Sabero & 764.435 & $1998 / 2002$ & Finalizado \\
La Ercina & 429.981 & 1998 & Finalizado \\
\hline \hline Abastecimiento de agua & & \\
\hline \hline Cistierna & 1.049 .663 & $2001 / 2003$ & Finalizado \\
Sabero & 2.166 .229 & $1998 / 2003$ & Finalizado \\
La Ercina & 669.150 & $2001 / 2003$ & Finalizado \\
\hline \hline TOTAL & 45.830 .668 & & \\
\hline \hline
\end{tabular}

FUENTE: Instituto para la Reestructuración de la Minería del Carbón y Boletín Oficial de Castilla y León 
Entre los proyectos del Programa de Infraestructuras del Plan 1998-2005 en la cuenca de Sabero destacan, por la cuantía de su presupuesto, el nuevo trazado y las reformas de la carretera CL-626 (Eje Subcantábrico), y el Museo Regional de la Minería (CUADRO 4).

El Eje Subcantábrico, la segunda carretera en importancia de la cuenca minera, es la vía que permite la articulación transversal de las comarcas carboneras leonesas y palentinas (motivo por el cual ha sido objeto de atención preferente en el Plan del Carbón). Además de enlazar sus cabeceras comarcales (Villablino, La Robla, Cistierna, Guardo, Cervera de Pisuerga y Aguilar de Campoo), engarza los ejes meridianos de conexión con la fachada cantábrica. En ella se han volcado las actuaciones en materia de transportes y comunicaciones que se han desplegado en Sabero, con el resultado de una notable mejora de la accesibilidad hacia el este (Guardo) y el oeste (La Robla).

No obstante, la calzada más importante, desde el punto de vista del desarrollo económico de la cuenca minera, es la N-625, una vía que, en territorio leonés, discurre en su mayor parte por el valle del Esla, y que enlaza Mansilla de las Mulas con la zona oriental asturiana (Cangas de Onís y Arriondas), sirviendo, además, de engarce entre las comarcas del este de la provincia de León. Ahora bien, el interés de la N-625 no está tanto en que permita la comunicación de la cuenca de Sabero con Asturias (o con Santander a través de la N-621, con la que enlaza a la altura de Riaño), como en que lo haga con la capital de la provincia y Valladolid. Por este motivo, su tramo más interesante, como lo demuestra su mayor volumen de tráfico, es el comprendido entre Mansilla de las Mulas y Cistierna. Entre estas dos localidades, la calzada discurre por un terreno completamente llano (mucho menos complicado que el anterior, por lo tanto); pero, pese a ello, sólo permite una velocidad de 71 a $80 \mathrm{~km} / \mathrm{h}$. Esto se debe a las numerosas travesías de poblaciones: un total de 16 en apenas 43 kilómetros, algo que entorpece enormemente la fluidez del transporte de personas y mercancías. Parece claro que una mejora de esta carretera, dado el papel que desempeña en la articulación espacial del territorio, habría tenido unos efectos mucho más intensos sobre el desarrollo de la cuenca minera que las reformas llevadas a cabo en el Eje Subcantábrico.

En el capítulo de transportes y comunicaciones, a los proyectos recogidos en el CUADRO 4 hay que añadir uno que afecta a varios territorios y que tiene al antiguo ferrocarril de La Robla como protagonista. En 1998, la Junta de Castilla y León y FEVE alcanzaron un acuerdo para reabrir la línea férrea León-Bilbao (el tramo entre León y Guardo estaba en funcionamiento desde 1994). El acuerdo contemplaba una inversión de 42 millones de euros para renovar el trazado, construir las infraestructuras necesarias para el transporte de viajeros y mejorar la calidad del tráfico de mercancías. La aportación procedente de los fondos de 
la reestructuración minera fue de 20,7 millones de euros. Cinco años más tarde, el 19 de mayo de 2003, volvió a funcionar el transporte ferroviario entre León y Bilbao. La línea, además de facilitar el desplazamiento de los habitantes de la cuenca de Sabero y de atesorar un indudable potencial turístico, facilita el intercambio de mercancías entre los territorios situados a lo largo de su recorrido, y también las importaciones y exportaciones a través del puerto de Bilbao.

En materia de infraestructuras turísticas, el proyecto más importante es el del Museo Regional de la Minería. Un proyecto que presenta dos novedades muy importantes respecto a los intentos precedentes de ponerlo en marcha. La primera consiste en que abarcará también la actividad siderúrgica, es decir, se reconoce la importancia histórica de la ferrería de San Blas. La segunda estriba en que el futuro Museo no será un elemento aislado, sino que formará parte de una red turística que se extenderá por las cuencas mineras leonesas y palentinas, una red que reforzará notablemente la capacidad de atracción de visitantes de cada proyecto.

El aspecto negativo radica en que el Museo se encontrara aún en proceso de ejecución a fines de 2005, cuando habían transcurrido catorce años desde que se produjo el cierre de las minas y, también, desde que se declaró la ferrería Bien de Interés Cultural. Es ésta una clara muestra del desinterés de los responsables del diseño y la ejecución de la política de reactivación. Desinterés que se ve reflejado, asimismo, en el lamentable estado en el que se encuentra el patrimonio industrial de la cuenca minera, sometido, desde el abandono de la minería, a continuos actos de expolio y destrucción, ante la pasividad de las distintas administraciones.

\section{UNOS RESULTADOS INSUFICIENTES PARA DETENER EL COLAPSO DEL TERRITORIO}

Durante los últimos años de la década de los noventa, se consolidaron los proyectos de SEPROLESA y NEAL, y, en el año 2000, se estableció en el polígono industrial de Vidanes Energía Viva, S. A. (ENERVISA), la empresa que, tanto por el volumen de sus inversiones como por el empleo generado, pasaría a ser la más importante de todas las ubicadas en la zona. Dos años después, otra sociedad vinculada al mismo grupo que ENERVISA, Complejo Cárnico Picos de Europa, S. A., se asentaría a su lado para completar el proceso productivo de la primera. Las actividades de estas dos sociedades incluyen la producción de forrajes y energía, la cría intensiva de ganado vacuno y su sacrificio.

El CUADRO 5 muestra el empleo, capital y volumen de ventas en 2003 de las cuatro compañías. El CUADRO 6 complementa al anterior, ofreciendo información sobre las inversiones realizadas y las subvenciones percibidas hasta el 31 
de diciembre de 2003. Estas últimas cubren, como se puede comprobar, la cuarta parte de las inversiones efectuadas. No hay duda de que los datos económicos globales son importantes. Resultan especialmente notables el volumen de ventas (62 millones de euros) y las inversiones (72 millones de euros). Sin embargo, su papel en la recomposición económica de la cuenca minera se ve limitado por el hecho de que no existan relaciones entre ellas y de que, salvo en el caso de $\mathrm{NEAL}^{14}$, tampoco sean muy importantes las establecidas con otras empresas de la comarca ${ }^{15}$.

Cuadro 5. Principales empresas ubicadas en la cuenca de Sabero como consecuencia de la reindustrialización: empleo, capital y ventas en 2003

\begin{tabular}{lrrrrrr}
\hline & \multicolumn{2}{c}{ Empleo } & \multicolumn{2}{c}{ Capital } & \multicolumn{2}{c}{ Volumen de ventas } \\
\cline { 2 - 7 } & \multicolumn{1}{c}{$N^{o}$} & \multicolumn{1}{c}{$\%$} & \multicolumn{1}{c}{$\%$} & \multicolumn{1}{c}{$m \epsilon$} & \multicolumn{1}{c}{$\%$} \\
\hline ENERVISA & 145 & 50,88 & 17.350 & 65,98 & 32.770 & 52,63 \\
SEPROLESA & 59 & 20,70 & 4.207 & 16,00 & 20.617 & 33,11 \\
Com. Cár. P. Europa & 48 & 16,84 & 1.761 & 6,70 & 5.991 & 9,62 \\
NEAL & 33 & 11,58 & 2.976 & 11,32 & 2.891 & 4,64 \\
\hline TOTALES & 285 & 100,00 & 26.294 & 100,00 & 62.269 & 100,00
\end{tabular}

FUENTE: Cuentas anuales

Junto a estas firmas, unas cuantas empresas de reducida dimensión se han ido localizando en las dos principales zonas industriales de la cuenca minera (Athes F. Energía Solar, S. L.; Mármoles la Rasa, S. L.; Industrias de la Madera Prado, S. L.; Tecoi Corte, S. L. etc.). Teniendo en cuenta, además, aquéllos proyectos surgidos a la sombra del proceso de reindustrialización en los tres municipios de la cuenca, pero no localizados en esas dos áreas industriales (Turismo, Campo, Mar e Iniciativas, S. L.; Hosteleros Leoneses, S. L.; etc.) podemos estimar que los puestos de trabajo generados directamente por todas las iniciativas empresariales ascienden a 330 .

\footnotetext{
${ }^{14}$ Entre los motivos que llevaron a David Álvarez (propietario de empresas como Eulen, S. A., Bodegas Vega Sicilia, S. A. o Flexiplán, S. A. ETT) a emprender este proyecto y localizarlo en la Montaña Oriental había uno muy especial: su estrecha vinculación con la comarca. Este empresario, natural de Crémenes, se fijó como objetivo la recuperación socioeconómica de la Montaña de León. Un fin que pretendía conseguir, no mediante el asentamiento de nuevas actividades industriales, sino potenciando algo que siempre había constituido uno de sus pilares: la ganadería extensiva.

${ }^{15}$ Una buena parte de las legumbres secas que utiliza SEPROLESA en su proceso productivo procede de países como Méjico, Argentina o EEUU, y llega a la Península por el puerto de Valencia. Los materiales auxiliares como los envases provienen de La Rioja y, también, de Valencia.
} 
Este volumen de empleo es muy inferior al que tenía Hulleras de Sabero en el momento del cierre (638 trabajadores), y no alcanza tampoco el objetivo que se fijó la Mesa de Sabero. Si retrocedemos algo más en el tiempo, la comparación resulta mucho más desfavorable: el empleo generado al amparo del proceso de reindustrialización apenas supone la tercera parte de la plantilla de Hulleras de Sabero en 1987 (1.006 trabajadores).

Cuadro 6. Principales empresas ubicadas en la cuenca de Sabero como consecuencia de la reindustrialización: inversiones y subvenciones hasta el 31-12-2003

\begin{tabular}{lcrrr}
\hline & \multicolumn{2}{c}{ Inversiones } & \multicolumn{3}{c}{ Subvenciones } \\
& $m \epsilon$ & $\%$ & $m \epsilon$ & $\%(1)$ \\
\hline \hline ENERVISA & 50.519 & 70,02 & 13.265 & 26,26 \\
Com. Cár. P. Europa & 9.337 & 12,94 & 1.922 & 20,58 \\
SEPROLESA & 7.032 & 9,75 & 1.867 & 26,55 \\
NEAL & 5.264 & 7,30 & 1.185 & 22,51 \\
\hline TOTALES & 72.152 & 100,00 & 18.239 & 25,28 \\
\hline \hline
\end{tabular}

(1) sobre inversiones. FUENTE: Cuentas anuales

Ahora bien, la recomposición del territorio no depende sólo de los puestos de trabajo generados directamente por los proyectos que han percibido las subvenciones vinculadas al proceso de reindustrialización. Cabe la posibilidad de que las empresas surgidas al amparo de este proceso hayan propiciado la creación de otras que por sus especiales características no figuren como beneficiarias de las ayudas procedentes de la reestructuración minera. Una posible forma de aproximarse a esta cuestión es analizar las cifras de empleo suministradas por los censos de población, si bien hay que tener presente que la información censal se refiere a los residentes en un municipio que trabajan, no a las personas que trabajan en ese municipio. Esto significa que, al tomar dicha información como un indicador de la estructura productiva del territorio, estaremos infravalorando el empleo generado en los territorios donde se ubican las unidades productivas, y sobrevalorando el del resto.

Cuadro 7. Ocupados en la cuenca minera de Sabero en 1991 y 2001

\begin{tabular}{lrrrr}
\hline & 1991 & 2001 & \multicolumn{2}{c}{ Variación } \\
\hline \hline Agricultura & 188 & 182 & -6 & $-3,19$ \\
Minería & 639 & 33 & -606 & $-94,84$ \\
Energía & 7 & 16 & 9 & 128,57 \\
Industria & 117 & 261 & 144 & 123,08 \\
Construcción & 211 & 360 & 149 & 70,62 \\
Servicios & 964 & 1.120 & 156 & 16,18 \\
\hline Total & 2.126 & 1.972 & -154 & $-7,24$ \\
\hline \hline
\end{tabular}

FUENTE: Junta de Castilla y León y Censo de Población y Viviendas de 2001 
Sin olvidar la precisión anterior, el CUADRO 7 refleja que la pérdida de empleo sufrida por la cuenca minera, desde 1991 hasta 2001, fue relativamente reducida, aproximadamente de un 7 por 100. Uno de los factores explicativos se encuentra, por supuesto, en el cambio de rumbo que experimentó su proceso de reindustrialización en 1996: las plantillas de SEPROLESA, NEAL y ENERVISA totalizaban 221 trabajadores en 2001, esto es, el 85 por 100 del empleo industrial de la cuenca. Como consecuencia de ese cambio de rumbo, el empleo del sector secundario creció un 123 por 100, un porcentaje que no tiene parangón en ninguna otra cuenca minera, y que contrasta con la disminución del 4 por 100 experimentada por la ocupación industrial en la provincia leonesa. Los efectos de arrastre de las industrias agroalimentarias asentadas en Sabero muy especialmente los procedentes de NEAL- son especialmente perceptibles en el empleo agrario, que se mantuvo prácticamente inalterado, al contrario de lo que aconteció en el conjunto de la provincia, donde el retroceso fue del 46 por 100 (hay que tener presente, también, que en varios territorios carboneros se aprecia un tímido renacer de la actividad agraria en respuesta a la crisis minera, aunque en todas las cuencas carboneras la evolución de este sector es más desfavorable que en la de Sabero).

Además del crecimiento del empleo industrial, destaca el de la construcción: un 71 por 100 frente al 28 por 100 de promedio provincial. Esta actividad ha jugado en la cuenca de Sabero, más que en ninguna otra (la segunda donde más creció fue la cuenca berciana con un incremento del 61 por 100), el típico papel de actividad refugio, amortiguando las consecuencias de la crisis. En cambio, el terciario, pese a ser el sector que más puestos de trabajo gana, presenta un escaso dinamismo, puesto que su crecimiento porcentual (16 por 100) resulta ser el más reducido de todas las cuencas mineras leonesas, salvo Valderrueda, y sólo alcanza el 45 por 100 de la media provincial. En el marco del proceso de terciarización económica que experimentan los países desarrollados, el exiguo crecimiento de los servicios en Sabero refleja, por un lado, la escasa atención prestada a estas actividades en el proceso de reversión del declive de esta cuenca, y, por otro, el hecho de que el cierre de una gran empresa minera precipite, a su vez, el de los establecimientos comerciales y de servicios que satisfacían la demanda de los trabajadores de la mina.

Obviamente, los datos del CUADRO 7 hay que ponerlos en el contexto de una crisis que, aunque mostró su máxima virulencia en 1991, venía arrastrándose desde muchos años antes. Sólo entre 1986 y 1991, los puestos de trabajo de Hulleras de Sabero se redujeron en 370. Unos cálculos aproximados nos dicen que, desde 1986 hasta 2001, la cuenca minera perdió más del 20 por 100 de su empleo, con el agravante de que, en el primero de los años citados, la mayor parte de los puestos de trabajo los generaban unidades productivas ubicadas en 
el territorio, mientras que, en 2001, un porcentaje significativo de los ocupados trabajaba en otros lugares ${ }^{18}$.

Las consecuencias demográficas del retroceso económico han sido demoledoras. Entre 1986 y 2005, la cuenca perdió más de 3.200 habitantes, esto es, el 35 por 100 de su población. Además, la intensidad del descenso ha ido aumentando progresivamente: la tasa media de disminución anual ha pasado del 1,65 por 100 entre 1986 y 1995 , al 2,58 por 100 entre 1995 y 2000, y, finalmente, al 2,87 por 100 entre 2000 y 2005. Las localidades más afectadas han sido los núcleos obreros del municipio de Sabero, es decir, los más directamente relacionados con la extracción de carbón. Sotillos, la localidad donde se levanta el castillete del pozo Herrera II, perdió el 69 por 100 de su población, que quedó reducida a 80 personas en 2005. En Saelices residían ese año 135 personas, un 51 por 100 menos que en 1986. Y la población del antaño populoso Olleros ni siquiera alcanzaba ya los 600 efectivos, tras haberse reducido casi un 47 por 100.

La aguda crisis en la que está sumida la cuenca de Sabero se ha dejado sentir también con fuerza en la localidad de Cistierna, cuya población se redujo un 24 por 100 entre 1986 y 2005. Los casi mil habitantes perdidos dejaron sus efectivos en 3.000, y le hicieron ceder a La Robla la condición de localidad más poblada del cuadrante nororiental leonés.

Al mismo tiempo que se reducía, se ha producido también un rapidísimo envejecimiento de la población de la cuenca. Entre 1991 y 2005, el grupo formado por los menores de 15 años cayó un 67 por 100, el índice de juventud se redujo un 54 por 100 y la edad media creció 8 años y se situó en 48 .

Pese a todo, de la simple comparación de los datos censales sobre empleo, podría derivarse un cierto optimismo si no fuera porque, tras ellos, se oculta una cuestión de trascendental importancia: los graves problemas económicos que sufren tres de las cuatro empresas en las que se basaba en 2005 la estructura productiva de la cuenca minera (CUADRO 8).

Resulta especialmente preocupante el hecho de que la crítica situación del tándem ENERVISA-Complejo Cárnico Picos de Europa determinara la declaración de ambas en concurso voluntario en septiembre de 2004, y que, a partir de entonces, entraran en un proceso de liquidación que ha concluido con el cierre de las dos compañías. Consecuentemente, los riesgos para el territorio, deriva-

\footnotetext{
${ }^{18}$ Según el Censo de Población y Viviendas de 2001, un 7,81 por 100 de los empleados residentes en la cuenca de Sabero empleaban más de 30 minutos en su desplazamiento hasta el lugar de trabajo. Dadas las reducidas dimensiones de esta cuenca minera, podemos estimar que, al menos esas personas, trabajaban fuera de ella.
} 
dos de la deslocalización o cierre de las compañías que operan en él, son elevados. No en balde, los resultados negativos conjuntos obtenidos en 2003 por las cuatro principales empresas se acercaron a los 16 millones de euros. El interrogante que surge es por qué no sólo se han asentado pocas empresas en la cuenca minera, sino que, además, las que lo han hecho han acabado padeciendo graves problemas económicos.

Cuadro 8. Resultados de las compañias ubicadas en la cuenca de Sabero (miles de euros)

\begin{tabular}{lrrrrrr}
\hline \hline & 1998 & 1999 & 2000 & 2001 & 2002 & 2003 \\
\hline \hline NEAL & -578 & -789 & -529 & -1.067 & -1.194 & -1.367 \\
SEPROLESA & -93 & 36 & -181 & 83 & 265 & 295 \\
ENERVISA & & & -2.855 & -5.316 & -6.954 & -14.080 \\
Com. Cár. P. de Europa & & & & & -460 & -555 \\
\hline \hline TOTALES & -671 & -753 & -3.565 & -6.300 & -8.343 & -15.707 \\
\hline \hline
\end{tabular}

FUENTE: Cuentas anuales

Los hechos demuestran que cuando la cuenca de Sabero contó con un mínimo de suelo industrial y ayudas más generosas a la localización empresarial que las aplicadas hasta 1995, varias compañías de cierta envergadura tomaron la decisión de asentarse en el territorio. Aunque en algunos casos el inicio de la actividad fue posterior, dichas decisiones se adoptaron en los años 1996 y 1997. ¿Por qué posteriormente, durante la vigencia del Plan del Carbón, ningún nuevo proyecto relevante se ha localizado en la cuenca de Sabero? Sin subestimar las mayores restricciones establecidas para el cobro anticipado de las ayudas, la respuesta a esta pregunta tiene mucho que ver, en nuestra opinión, con la dotación de suelo industrial, concretamente con su escasez creciente en la cuenca minera y su oferta creciente en el resto de la provincia.

Cuando entró en vigor el Plan del Carbón, la relativa escasez de suelo industrial que padecía León queda de manifiesto en las 494 hectáreas que totalizaban los 27 polígonos y zonas industriales existentes (BENITO ET AL., 2006). Los últimos creados (desde 1992) eran, además, de pequeño tamaño. Sólo tres polígonos superaban las 10 hectáreas: El Tesoro (Valencia de Don Juan), Vidanes y el Parque Industrial del Bierzo (Ponferrada). De los tres, únicamente los dos últimos podían beneficiarse de las ayudas procedentes de la reestructuración minera. Entre las zonas industriales más recientes se encontraban también los otros dos polígonos de la cuenca de Sabero: Herrera I y II. Todo esto significa que, a mediados de los noventa, no había muchos territorios en la provincia que, por disponibilidad de suelo industrial y ayudas a la localización empresarial, pudieran competir con la cuenca minera. 
A partir de 1998, la situación cambia diametralmente. Primero, con la creación de polígonos, generalmente de pequeño tamaño, en zonas susceptibles de percibir las ayudas al desarrollo alternativo del Plan del Carbón, y, desde 2003, con numerosos proyectos entre los que se encuentran asentamientos industriales tan importantes como el Parque Tecnológico de León y los polígonos industriales de Onzonilla, Valdefresno, Villadangos, Mansilla de las Mulas o Cubillos del Sil.

El resultado ha sido que, en 2005, la oferta de suelo industrial en León (incluyendo los proyectos en ejecución) totalizaba 1.511 hectáreas en 52 asentamientos. Pues bien, de ellos la mitad son posteriores a 1997, y, lo que es más relevante, su superficie (1.017 hectáreas) representa más de las dos terceras parte del suelo industrial de la provincia. Es preciso tener presente, además, que, en esta última etapa, también se ha producido una notable ampliación de la zona industrial de la localidad palentina de Guardo, una zona que se encuentra muy próxima a la cuenca minera de Sabero (sólo del Plan del Carbón se han destinado a ello más de 3,8 millones de euros entre 1999 y 2002).

En la nueva coyuntura, por tanto, las posibilidades con que cuenta un territorio con las características de la cuenca de Sabero para atraer nuevas inversiones empresariales son muy escasas, y, previsiblemente, sólo aumentarán en la medida en que se vayan saturando los espacios más favorables para la localización empresarial, algunos de los cuales ya han previsto desarrollos importantes. Las futuras ampliaciones de la exigua dotación de suelo industrial de la cuenca minera o la oferta de parcelas a precios muy reducidos, son, sin duda, aspectos positivos, pero insuficientes para compensar sus desventajas respecto a los polígonos ubicados junto a las aglomeraciones urbanas o las grandes redes de comunicación. El índice de accesibilidad que elabora Benito (BENITO ET AL., 2006), con las tres zonas industriales de la cuenca de Sabero ocupando posiciones muy retrasadas en la clasificación correspondiente, ilustra una parte del problema. Los condicionantes del proceso de reindustrialización referidos al territorio con los que comenzábamos nuestra exposición completan el elenco de dificultades al que se enfrenta, todavía hoy, el desarrollo del antiguo territorio minero.

\section{CONCLUSIONES}

En espacios atrasados o menos desarrollados, como las cuencas mineras leonesas (es decir, en territorios especializados en actividades primarias o extractivas en las que el nivel de inversión en otros sectores es muy bajo), es prácticamente nula la probabilidad de que la reversión del declive se produzca de forma espontánea a través de relaciones de mercado. Al menos, no sería realista confiar en que el impulso inicial de la reactivación se genere desde el interior de territorios que presentan tal cúmulo de características negativas: ausencia de eco- 
nomías de aglomeración, lejanía de los grandes ejes de comunicación, infraestructuras deficientes, capital humano insuficiente, instituciones ineficientes, falta de espíritu emprendedor, etc.

Consecuentemente, la intervención pública deviene en el elemento fundamental para afrontar la crisis. Para ser más precisos: las políticas de desarrollo alternativo bien diseñadas son condición necesaria para romper la dinámica negativa de estos espacios geográficos. El problema estriba en que no son condición suficiente, puesto que el desarrollo depende, de la intensidad de la crisis y, en última instancia, del propio territorio, de que sea capaz de aprovechar el impulso generado por la intervención pública de forma que llegue un momento en el que ya no la necesite para mantenerse en la senda del desarrollo. De aquí se deduce que el fracaso puede deberse a una política deficiente o a que el territorio carece del potencial mínimo que se requiere para que la espiral del desarrollo se ponga en movimiento.

En nuestra opinión, el proceso de reindustrialización de la cuenca de Sabero se ha topado con el gran obstáculo que representa la tendencia a la concentración espacial de la actividad económica (KRUGMAN, 1992). Una tendencia que se manifiesta en todos los niveles: desde el nacional hasta el comarcal. La aglomeración de la actividad y la población se produce en determinados lugares debido a la existencia de rendimientos crecientes, y se ve potenciada por la mejora y el abaratamiento de los transportes (si esta idea es correcta, la mejora de las infraestructuras de transporte puede acelerar el declive industrial de las zonas más atrasadas, en lugar de favorecer su desarrollo). Cuando la aglomeración alcanza un determinado nivel, surgen economías externas que confieren una ventaja competitiva a las empresas allí instaladas y hacen que el lugar sea más atractivo aun para la localización empresarial. Esas economías externas pueden adoptar múltiples formas, desde una abundante dotación de mano de obra cualificada, hasta la más fácil difusión de la información, o la presencia de proveedores especializados o de una tupida red de servicios (MARSHALL, 1890). Pero todas permiten a las empresas o producir mejor o hacerlo a unos costes inferiores (KRUGMAN Y OBSTFELD, 1993).

En principio, el proceso acumulativo descrito podría iniciarse en cualquier lugar; pero, lógicamente, será más probable que lo haga en aquéllos que exhiban características más favorables para la localización empresarial. En cualquier caso, aquellos territorios en los que se dé primero gozarán de una ventaja difícil de neutralizar: las empresas que se instalen en cualquier otro sitio, sin el beneficio de las economías externas, no podrán competir. Lo determinante del desarrollo económico no es, pues, la dimensión de las empresas, sino la formación de redes de empresas que permitan generar dichas economías y reducir los costes de transacción (VÁZZUEZ BARQUERO, 1999). Las propiedades del contexto 
industrial se convierten, así, en decisivas, hasta el punto de que el problema fundamental de una pequeña compañía puede residir, no en su tamaño, sino en el hecho de estar aislada (PYKE, 1990).

Esta teoría explica dos hechos recurrentes que aparecen a lo largo del proceso de reindustrialización de Sabero: el escaso número de empresas interesadas en ubicarse en la cuenca minera, y los enormes problemas económicos que, con la única excepción de SEPROLESA, padecen todas aquéllas que han decidido establecerse en la zona.

Ahora bien, también la gestión política del declive tiene su cuota de responsabilidad en la situación a la que se ha llegado. Esta política se ha caracterizado por su descoordinación con el desmantelamiento de la minería, por la insuficiencia de los recursos destinados a la reindustrialización (al menos hasta 1996) y por la falta de criterios a la hora de seleccionar las intervenciones y establecer prioridades entre ellas. La demora en la ejecución de un proyecto, tan indiscutiblemente positivo para el desarrollo territorial como el Museo Regional de la Minería, es una prueba de ello. No podemos saber con certeza qué es lo que habría ocurrido si, desde un principio, las administraciones públicas hubieran realizado un mayor esfuerzo financiero, si se hubiera dotado al territorio de más suelo industrial, si se hubiera mejorado la accesibilidad (actuando en la carretera N-625 entre Mansilla de las Mulas y Cistierna), si se hubiera dado prioridad a las infraestructuras turísticas que, hoy todavía, son un proyecto o están en fase de ejecución. Sólo contamos con la evidencia de lo que aconteció en 1996 y 1997, cuando la competencia con otros territorios para atraer inversiones empresariales no era tan acentuada como en la actualidad, y el proceso reindustrializador llegó a disponer de unas mínimas condiciones en lo que a suelo industrial y ayudas financieras se refiere. El gran interrogante es, por tanto, si con una política de reactivación más acertada, desplegada con suficiente intensidad desde un principio, se habría conseguido transformar progresivamente el territorio, haciéndolo más favorable para la localización empresarial.

Se puede argüir, con razón, que ni siquiera una política bien diseñada es capaz de modificar a corto plazo determinadas características. Las instituciones informales, el espíritu empresarial, la "atmósfera industrial", aspectos vitales del desarrollo, no se improvisan, sino que son el resultado de un largo proceso histórico (NORTH, 1990). Pero, si el objetivo es el desarrollo territorial, este lento proceso debe comenzar en algún momento y alguien tiene que asumir los costes de mantenerlo abierto, sabiendo que el éxito no está garantizado.

Estas ideas nos devuelven a las consideraciones que hacíamos al comenzar este apartado de conclusiones: una política de reactivación adecuada puede fracasar en su intento de detener el declive de un territorio, una inadecuada fracasará 
necesariamente. En el caso concreto de Sabero, hemos intentado demostrar que es esto último lo que ha sucedido, que la política de inversión del declive ha sido inadecuada, y que, a la vista de su escaso bagaje, del tiempo transcurrido y de la precariedad de las inversiones empresariales que aún se mantienen, su fracaso es manifiesto.

\section{BIBLIOGRAFÍA}

Benito Del Pozo, P. (1991): El espacio industrial en Asturias, Barcelona, Oikos-Tau. Benito Del Pozo, P.; LóPez GonZÁlez, A., Y GonZÁlez RABANAL, N. (2006): Suelo industrial y territorio en León, León, Universidad de León.

Celis SÁNCHEZ, J.; HerRero MANSO, J., Y RodríGUeZ FernándeZ, M. A. (1997): Museo Minero Regional Ferrería de San Blas, Informe.

CORTIZO ÁlvAREZ, J. (1996): «La crisis minera del Valle del Sil», La disponibilidad de recursos y el desarrollo industrial leonés, León, Universidad de León, págs. 31-43.

CORTIZO Álvarez, T. (1977): Las cuencas mineras leonesas (aproximación a su estudio geográfico), León, Institución Fray Bernardino de Sahagún de la Excma. Diputación Provincial.

DAYNAC, M. (1996): «Reconversión y dinámicas territoriales: investigaciones recientes. Análisis de las metodologías utilizadas en reconversión y mutación», Economía Industrial, número 308, págs. 53-66.

HiRsCHMAN, A. (1958): The Strategy of Economic Development, New Haven, Yale University Press (traducción española: La estrategia del desarrollo económico, México, Fondo de Cultura Económica, 1961).

Krugman, P. (1992): Geografia y comercio, Barcelona, Antoni Bosch.

KRUGMan, P., y OBSTFELD, M. (1993): Economía internacional. Teoría y política, Madrid, McGraw-Hill.

LóPEZ TRIGAL, L. (1982): «Jerarquía y áreas de influencia en las Ciudades de Castilla y León», I Congreso de Geografía de Castilla la Vieja y León, Burgos, Consejo General de Castilla y León, págs. 315-327.

LÓPEZ TRIGAL, L. (1991): La inmigración extranjera en León. Análisis de su estructura y distribución en la provincia y las cuencas mineras, León, Universidad de León.

LóPEZ TRIGAL, L. (dir.) (1994): La migración de portugueses en España, León, Universidad de León.

LÓPEZ TRIGAL, L. (1996), «Introducción a la industria y minería leonesa», en La disponibilidad de recursos y el desarrollo industrial leonés, León, Universidad de León, págs. 11- 29.

LóPEZ TRIGAL, L. (dir.) (2002): La población inmigrante en Castilla y León, Documento técnico, CES.

MARShall, A. (1890): Principles of Economics, London (traducción española: Principios de Economía, Madrid, Aguilar, 1963).

MAURíN ÁLVAREZ, M. (1987): «Introducción al estudio geográfico de las cuencas mineras españolas», Ería, número 12, págs. 5-24.

NorTH, D. (1990): Institutions, Institutional Change and Economic Performance, Cambridge University Press (traducción española: Instituciones, cambio institucional y desempeño económico, México, Fondo de Cultura Económica, 1993). 
PASCUAL RUIZ-VALDEPEÑAS, H. (1993): Reconversión y reindustrialización en España: los nuevos dinamismos espaciales, Universidad de Valladolid.

Pyke, F.; BeCATtini, G., Y SENGENBERGER, W. (comps.) (1990): Industrial districts and inter-firm co-operation in Italy, Organización Internacional del Trabajo (traducción española: Los distritos industriales y las pequeñas empresas, Ministerio de Trabajo y Seguridad Social, 1992).

SEN RodRíGUEZ, L. (1993): La minería leonesa del carbón, 1764-1959: una historia económica, León, Universidad de León.

VÁZQUEZ BARQUERO, A. (1999): Desarrollo, redes e innovación: lecciones sobre desarrollo endógeno, Madrid, Pirámide.

VIDAL ENCINAS, J. M., Y ÁlVAREZ ORDÁS, J. C. (2002): «La protección del patrimonio arqueológico industrial en la provincia de León: el caso de la ferrería de San Blas», Tierras de León, número 115, págs. 97-121.

\section{FUENTES}

Actas de la Mesa para la Reindustrialización del Área de Sabero.

Boletín Oficial de Castilla y León.

Cámara Oficial de Comercio e Industria de León: Censo de contribuyentes por licencia fiscal al 31 de diciembre de 1989.

Censos de población de 1981, 1991 y 2001.

Cuentas anuales de ENERVISA, NEAL, SEPROLESA y Complejo Cárnico Picos de Europa.

Diario de León.

Dirección General de Estadística de la Junta de Castilla y León: datos municipales de empleo del Censo de Población de 1991 desglosados por sectores.

Estadística General de Producción, Importación y Distribución Directa de Carbones Minerales.

Instituto para la Reestructuración de la Minería del Carbón y Desarrollo Alternativo de las Comarcas Mineras: datos internos.

Nomenclátor.

Padrones municipales. 


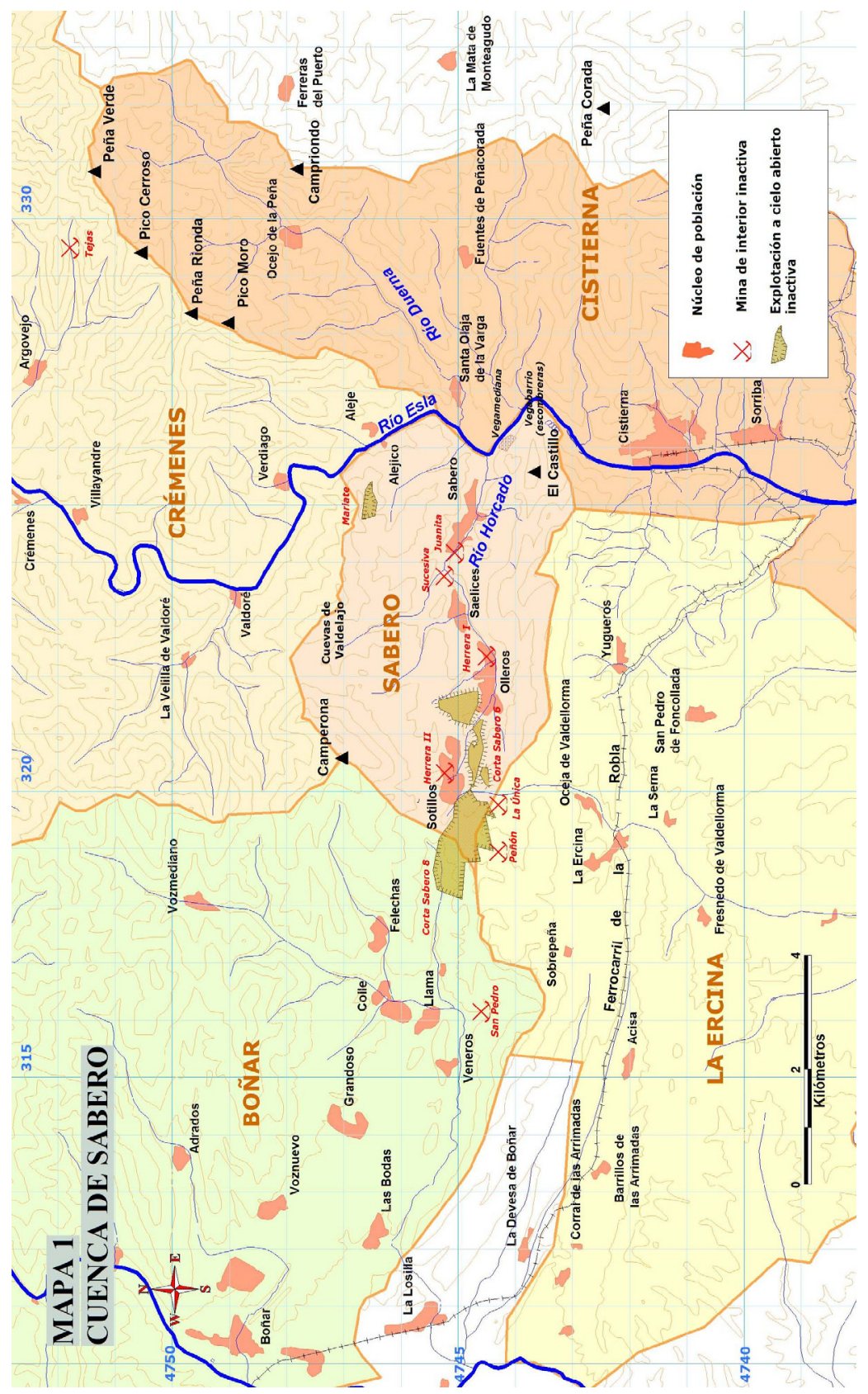

